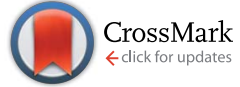

Cite this: RSC Adv., 2015, 5, 61290

Received 13th April 2015 Accepted 6th July 2015

DOI: $10.1039 / c 5 r a 06599 b$

www.rsc.org/advances

\section{Low-temperature nanoredox two-step sintering of gelatin nanoskin-stabilized submicrometer-sized copper fine particles for preparing highly conductive layers $\dagger$}

\author{
Tetsu Yonezawa, ${ }^{*}$ Hiroki Tsukamoto and Masaki Matsubara \\ A conductive paste was prepared with submicrometer-sized copper fine particles that were coated by a \\ gelatin nanoskin. The average particle size was ca. $130 \mathrm{~nm}$. After drying, an oxidation-reduction two- \\ step sintering process was proposed for these submicrometer-sized copper fine particles to obtain low- \\ resistivity layers at a very low temperature. The optimized conditions gave a low resistivity of $8.2 \times 10^{-6}$ \\ $\Omega \mathrm{cm}$, even when the particles were covered by a common polymer. Our results suggest that the \\ formation of the small copper oxide prominences on the surface of the copper fine particles could be \\ reduced at low temperatures, forming connected submicrometer-sized metallic copper particles.
}

\section{Introduction}

The unique properties of metal nanoparticles and fine particles provide possible new product developments. ${ }^{1-4}$ At present, nanotechnology is a technology that cuts across different boundaries, including use in construction and composite materials, ${ }^{5}$ as catalysts, ${ }^{6-9}$ antibacterial coatings, ${ }^{10,11}$ biosensors, ${ }^{12}$ plasmonic photo devices ${ }^{13}$ and electrical devices,${ }^{14-19}$ in addition to some consumer products. The steady increase in nanoparticle and fine particle use is accompanied with larger production, requiring development of the handling and processing of such materials.

Moreover, the recent intensive progress in printed electronics has been based on the development of materials, including nanomaterials. ${ }^{15-18}$ In particular, conductive inks and pastes that consist of metal nanoparticles and fine particles are key materials in printed electronics, as they provide a costsaving wet process application. ${ }^{16-23}$ This modern printing process technology is expected to open the door for new manufacturing techniques that increase productivity while reducing energy and resource consumption compared to conventional methods. For flexible, lightweight, and

Division of Materials Science and Engineering, Faculty of Engineering, Hokkaido University, Kita 13 Nishi 8, Kita-ku, Sapporo, Hokkaido 060-8628, Japan. E-mail: tetsu@eng.hokudai.ac.jp

$\dagger$ Electronic supplementary information (ESI) available: Schematic illustration of the six measuring points of $\mathrm{Al}_{2} \mathrm{O}_{3}$ substrate for resistivity measurements (Fig. S1); XRD pattern of as-synthesized copper fine particles on a glass substrate (Fig. S2); TG charts of the paste vehicle including ethyl cellulose under air and $\mathrm{N}_{2}$ flow (Fig. S3); TG and temperature charts of the commercially available $\mathrm{Cu}_{2} \mathrm{O}$ particles under $3 \% \mathrm{H}_{2}$ in $\mathrm{N}_{2}$ gas mixture (Fig. S4); SEM image of commercially available $\mathrm{Cu}_{2} \mathrm{O}$ particles (Fig. S5). See DOI: 10.1039/c5ra06599b inexpensive electronic devices, such as smart labels that include radio-frequency identification (RFID), organic light-emitting diodes (OLEDs), flexible displays, printed electronics will be frequently used to make cost-effective and eco-friendly products. ${ }^{24}$ Noble metals, in particular the silver nanoparticle inks, are highly stable and often used for producing conductive films. ${ }^{16}$ However, the high material cost still hinders their use in large-scale printed electronic applications. Silver migration is also an important issue, as it can degrade device performance. Conducting polymers are other possible alternatives, but in many cases, their conductivity is insufficient for industrial use. In contrast, copper nanoparticles and fine particles are attractive from a cost and anti-migration viewpoint. Recently, the synthesis of copper nanoparticles and fine particles has attracted considerable interest. ${ }^{25-42}$ However, due to their poor resistance to oxidation, only a few papers have been reported thus far on their practical application as electro-conductive materials. From the printed electronic material viewpoint, the presence of copper oxides on the particle surface has negative consequences, as it increases the required sintering temperature and reduces the electro-conductivity. To overcome the copper nanoparticle and fine particle oxidation issue, numerous attempts have been made, including new sintering technologies, ${ }^{26-33}$ antioxidation, ${ }^{34}$ encapsulation of the copper surface with polymers, ${ }^{35-38}$ organic molecules, ${ }^{39}$ metal oxides, ${ }^{40}$ and metal shells. ${ }^{41}$

Yabuki et al. applied a two-step sintering method to a copper layer formed from a copper ink containing $20 \mathrm{~nm}$ copper nanoparticles covered by a thin carbon layer. ${ }^{27} \mathrm{~A} 1 \mathrm{~h}$ annealing step in air followed by a $1 \mathrm{~h}$ reductive sintering step under $5 \%$ hydrogen $\left(\mathrm{H}_{2}\right)$ in argon $(\mathrm{Ar})$ gas mixture at $300{ }^{\circ} \mathrm{C}$ provided a copper layer with a low resistivity of $1.4 \times 10^{-5} \Omega \mathrm{cm}$. We 
previously applied a similar two-step sintering method to a layer obtained from a copper ink containing $46 \mathrm{~nm}$ copper nanoparticles covered by gelatin. ${ }^{43}$ After annealing the copper layer at $200{ }^{\circ} \mathrm{C}$ under $10 \mathrm{ppm}$ oxygen $\left(\mathrm{O}_{2}\right)$ in nitrogen $\left(\mathrm{N}_{2}\right)$ gas flow for $1 \mathrm{~h}$, it was then reduced at $250{ }^{\circ} \mathrm{C}$ by $3 \% \mathrm{H}_{2}$ in $\mathrm{N}_{2}$ gas flow for $1 \mathrm{~h}$. A low resistivity of $5.1 \times 10^{-6} \Omega \mathrm{cm}$ was obtained. Recently, we have also reported two-step sintering process at $250{ }^{\circ} \mathrm{C}$ in air and in $3 \% \mathrm{H}_{2}$ in $\mathrm{N}_{2}$ gas with ecologically prepared aminestabilized copper fine particles and discussing the formation of copper oxide nano-objects on the particle surface and the effect of sintering temperatures on resistivity. ${ }^{44}$ However, to our best knowledge, a detailed discussion on the mechanisms of the low-temperature two-step sintering process of polymerstabilized copper fine particles that produces highly conductive copper layers at relatively low temperature as $200^{\circ} \mathrm{C}$ has not been discussed so far.

In our previous study, we proposed the use of gelatin as a stabilizer and antioxidation reagent for copper nanoparticles and fine particles prepared by a chemical reduction of copper(II) oxide $(\mathrm{CuO})^{35}$ and a copper salt. ${ }^{36} \mathrm{CuO}$ is a solid copper source containing oxygen as the only counter anion. From the contamination point of view, $\mathrm{CuO}$ is the ideal metal source candidate for copper fine particles used in conductive inks and pastes. Furthermore, this process can be performed at a copper concentration of $1 \mathrm{~mol} \mathrm{dm}^{-3}$ (i.e., $64 \mathrm{~g}$ of $\mathrm{Cu}$ per $1 \mathrm{dm}^{3}$ of water),$^{35}$ which is significantly higher than the usual chemical reduction process. Once these gelatin-stabilized copper fine particles were obtained, conductive pastes were prepared and used as the inner electrode material in a multi-layer ceramic capacitor (MLCC). ${ }^{14}$ We also formed a conductive copper layer by a two-step sintering process at $200{ }^{\circ} \mathrm{C}$ and $250{ }^{\circ} \mathrm{C}$ using the $\mathrm{Cu}$ nanoparticles coated with a gelatin layer ${ }^{43}$ however, this previous study could not reveal the mechanism of this lowtemperature sintering. Moreover, this copper nanoparticle ink did not contain any sintering binders, which are usually used in industrial processes.

In this paper, we describe the low-temperature sintering process of copper films made from the gelatin-stabilized copper fine particle ink using ethyl cellulose as an organic binder, via the two-step annealing method. The detailed mechanism of this two-step annealing was examined through X-ray diffraction (XRD) and electron microscopy analyses. The oxidative annealing produces smaller prominences of $\mathrm{Cu}_{2} \mathrm{O}$, which play a key role in the sintering process. The resultant conductive copper films show a low resistivity of $8.2 \times 10^{-6} \Omega \mathrm{cm}$. Compared to our previous studies, we performed a sintering process that simulated an industrial process due to using a copper ink that included organic binders.

\section{Experimental}

\section{Materials}

The CuO microparticles used as the metal source were supplied from Nisshin Chemco (Kyoto, Japan) and had an average diameter of approximately $4 \mu \mathrm{m}$. $\mathrm{Cu}_{2} \mathrm{O}$ was purchased from Kanto (Japan). Hydrazine monohydrate, used as a reducing reagent, and aqueous ammonia $(28 \%)$ for $\mathrm{pH}$ adjustment were purchased from either Wako or Junsei Chemical (Japan). Gelatin (cow origin, $\mathrm{MW}=c a .20000$ ) and a polyamine type dispersed agent were supplied from Nitta Gelatin NA Inc. (Osaka, Japan). EC vehicle, containing $10 \mathrm{wt} \%$ of ethyl cellulose, was purchased from Nisshin-Kasei Co., Ltd., (Japan). Water was purified by an Organo/ELGA Purelabo ultra (>18 M $\Omega)$.

\section{Preparation of the copper fine particles}

The detailed preparation procedure is described in Fig. 1. The copper fine particles were prepared following a method described previously. ${ }^{35} 32 \mathrm{~g}$ of gelatin was dissolved into hot water $\left(950 \mathrm{~cm}^{3}, 60{ }^{\circ} \mathrm{C}\right)$, and then the $\mathrm{CuO}$ microparticles $(80 \mathrm{~g})$ were introduced into this solution. Then, aqueous ammonia $(28 \%)$ was added to adjust the dispersion $\mathrm{pH}$ to $c a$. 11 . The reduction of $\mathrm{CuO}(80 \mathrm{~g}, 1 \mathrm{~mole})$ to metallic copper using the hydrazine monohydrate $\left(120 \mathrm{~cm}^{3}\right)$ was carried out at $80^{\circ} \mathrm{C}$ in air with stirring for $2 \mathrm{~h}$. The fine particles were then collected by decantation after introducing a saturated aqueous citric acid solution to reduce the dispersion $\mathrm{pH}$ to $c a .8 .5$ and washed with water twice and ethanol twice again, followed by drying the collected copper fine particles at $60{ }^{\circ} \mathrm{C}$ under $\mathrm{N}_{2}$ atmosphere.

\section{Preparation of the copper fine particle paste and conductive copper film}

In order to prepare a paste of the copper fine particles, the collected copper particle powder was first ground by an automatic mortar for $30 \mathrm{~min}$, pulverized by a blender, and mixed with $5 \mathrm{wt} \%$ of a dispersing agent. Then the mixture was dispersed into $50 \mathrm{wt} \%$ of commercially available paste vehicle using a mixer and an emulsifier. The obtained copper paste was deposited on a glass and an aluminum oxide $\left(\mathrm{Al}_{2} \mathrm{O}_{3}\right)$ substrates (supplied by Furuuchi Chem., Japan) by the doctor blade method for a film with $40 \mu \mathrm{m}$ thickness and $20 \mathrm{~mm}$ width. After drying in $\mathrm{N}_{2}$ at $60^{\circ} \mathrm{C}$ for $1 \mathrm{~h}$, the $\mathrm{Al}_{2} \mathrm{O}_{3}$ substrate was cut into 20 $\mathrm{mm} \times 20 \mathrm{~mm}$ pieces and annealed at $200{ }^{\circ} \mathrm{C}$ in air for $4 \mathrm{~h}$, and subsequently reduced in $3 \% \mathrm{H}_{2}$ in $\mathrm{N}_{2}$ gas. The reductive annealing times were varied from 1 to $4 \mathrm{~h}$ to determine the reduced state of copper. The gas flow rates were adjusted to $2 \mathrm{dm}^{3} \min ^{-1}$ for both air and $3 \% \mathrm{H}_{2}$ in $\mathrm{N}_{2}$ gas during annealing.

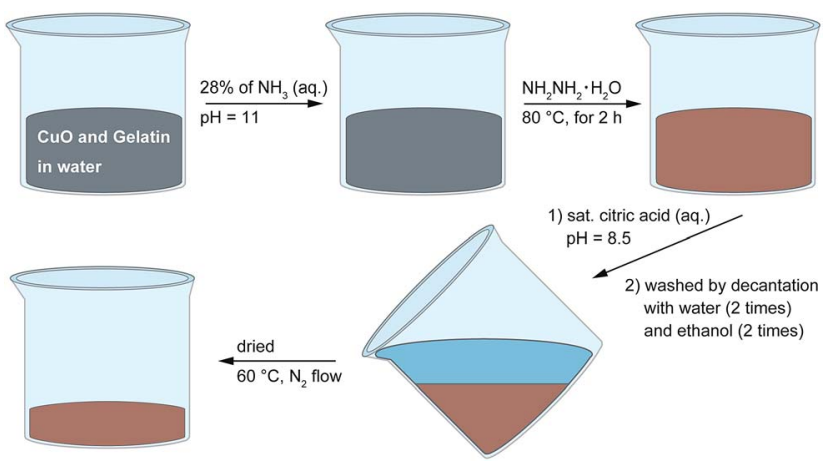

Fig. 1 Schematic illustration of the detailed preparation procedure for obtaining gelatin nanoskin-stabilized copper fine particles. 


\section{Characterization}

Scanning electron microscopic (SEM) images of the particles were performed using a JEOL JSM-6701F field emission type SEM with an acceleration voltage of $15 \mathrm{kV}$. In this study, secondary electron observation images (SEI) and back scattered electron images for observation of the composition of samples (BEI-COMPO) were taken. SEI gives topological information of sample surfaces. BEICOMPO was used to understand the composition of the surface of the samples. Heavier elements show brighter contrasts. XRD patterns were obtained with a Rigaku Mini Flex II $(\mathrm{Cu} \mathrm{K} \alpha)$. Transmission electron microscopic (TEM) images were obtained with a Hitachi $\mathrm{H}-9500$ with an acceleration voltage of $300 \mathrm{kV}$. The TEM samples included the annealed copper layer that was detached from the $\mathrm{Al}_{2} \mathrm{O}_{3}$ substrate by scratching, then dispersed in ethanol and applied to carbon-coated copper grids. The thermal properties of the copper fine particles and copper oxide particles were measured by thermogravimetric (TG) analysis with a Shimadzu DTG-60H. The TG measurements of the copper paste and the sintered copper film were carried out under air. After the measurement up to $600{ }^{\circ} \mathrm{C}$, all metallic copper was oxidized to $\mathrm{CuO}$ and organic molecules were supposed to be totally decomposed and eliminated. The sheet resistances of the copper films were obtained using a four-point probe method (Loresta-GP, MCP-T610, Mitsubishi Chemical Analytech Co., Japan). In order to obtain reproducible data, six points were measured with a four point probe per a copper layer, as shown in Fig. S1, $\dagger$ and the average values are displayed here.

\section{Results and discussion}

\section{Preparation and characterization of the gelatin-nanoskin stabilized copper fine particles}

Copper fine particles with uniform sizes could be obtained readily and reproducibly by our process. ${ }^{35}$ After the reaction and pH control by citrate addition, the obtained copper fine particles were collected by decantation, washed by water and ethanol to remove excess gelatin molecules at room temperature, and dried under $\mathrm{N}_{2}$ flow at moderated temperature $\left(60{ }^{\circ} \mathrm{C}\right)$. The powders showed no obvious particle oxidation, and no color change of the dried particles was observed for several weeks, as reported elsewhere. ${ }^{35}$ The XRD pattern of the as-prepared copper fine particles is shown in Fig. S2. $\dagger$ As shown in Fig. 2a, the particles were uniform and nearly spherical, with an average particle size and a size distribution of $120 \pm 35 \mathrm{~nm}$. The surface of the particles was covered by the gelatin layer, ${ }^{36}$ forming a smooth surface with no small dots observed. Gelatin molecules have amino groups and mercaptan groups in their side chains, and they are coordinated to the particle surface. If surface of metallic copper particles is oxidized, small dots should be observed because of the difference of density between metallic $\mathrm{Cu}$ and copper oxide $\left(\mathrm{CuO}\right.$ or $\left.\mathrm{Cu}_{2} \mathrm{O}\right)$. The copper fine particles were formed by the gradually supply of $\mathrm{Cu}^{2+}$ ion from the surface of $\mathrm{CuO}$ microparticles in the presence of excess amount of hydrazine. Thus, supply rate of $\mathrm{Cu}^{2+}$ ion limited the reaction, resulting in the formation of submicron sized uniform copper fine particles.
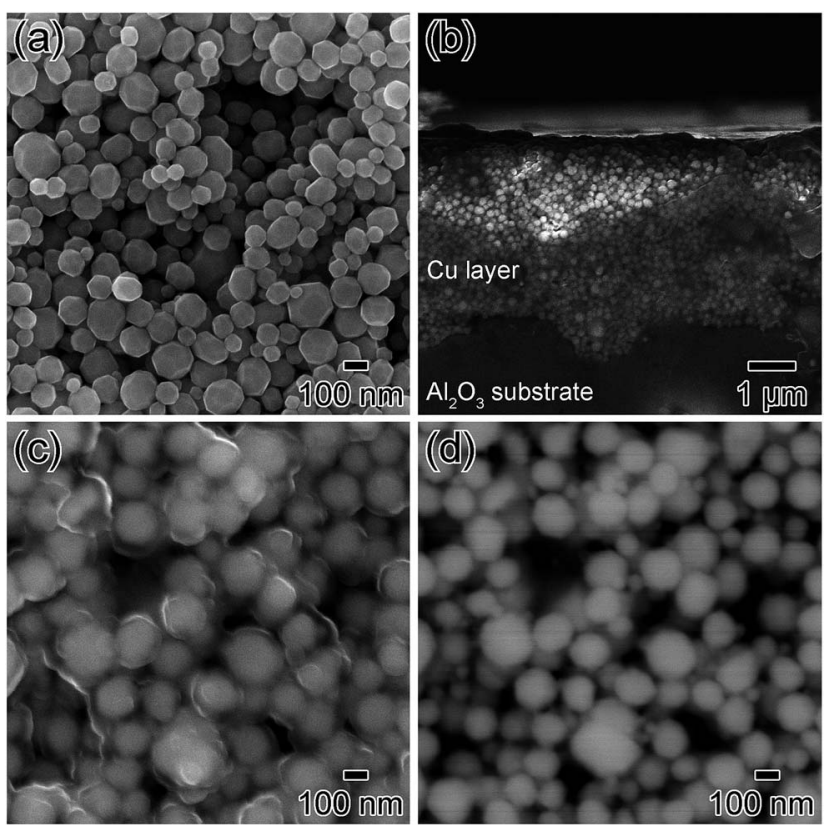

Fig. 2 SEM images of the copper particles prepared and used in this study. (a) The as-synthesized copper particles. (b) A cross-sectional image of copper particles printed on an $\mathrm{Al}_{2} \mathrm{O}_{3}$ substrate. (c) $\mathrm{A} S \mathrm{SEI}$ (secondary electron) image of the copper particles on the printed layer surface. (d) A BEI-COMPO (back scattered electron for composition) image, detecting reflected electrons, of the copper particles on the printed layer surface.

\section{Preparation of the copper fine particle paste and printing}

After purification of the collected copper fine particles, they were then re-dispersed to form a viscous electro-conductive paste. The liquid component of the paste vehicle evaporated at around $120{ }^{\circ} \mathrm{C}$ and the ethyl cellulose decomposed at temperatures over $210{ }^{\circ} \mathrm{C}$ (Fig. S3 $\dagger$ ). The obtained copper paste was stable and could be printed with a uniform thickness onto an $\mathrm{Al}_{2} \mathrm{O}_{3}$ substrate using doctor blading. After printing, the copper layer was dried at $60{ }^{\circ} \mathrm{C}$ under $\mathrm{N}_{2}$ flow to avoid oxidation. Fig. $2 \mathrm{~b}-\mathrm{d}$ show the surface and cross-section SEM images of the as-printed copper particle layers. Copper particle layers with a flat surface and a relatively uniform thickness of $c a$. $4.0 \mu \mathrm{m}$, ranging from 3.0 to $5.0 \mu \mathrm{m}$, were obtained (Fig. 2b). Fig. 2c and d are the surface SEM images at the same position taken with a secondary electron detection (SEI) mode and back scattered detection for composite observation (BEI-COMPO) mode. In a BEI-COMPO image, the image contrast is affected not only by the topological structure but also by the atomic number of the materials. Therefore, the bright contrast in BEI-COMPO images shows copper metallic cores of the particles (Fig. 2d). By comparing these two images, one can clearly understand that the copper fine particles are completely covered by polymer layers, including the gelatin, dispersant, and ethyl cellulose. Copper metallic cores did not contact directly to others due to these polymer layers. According to these polymer layers, these as-printed copper particle layers were not electro-conductive. 


\section{Copper layers after annealing in air and hydrogen-nitrogen mixed gas}

The copper thin layers on substrates were first annealed at $200{ }^{\circ} \mathrm{C}$ under airflow to effectively remove the organic components, and then subsequently annealed under $3 \% \mathrm{H}_{2}$ in $\mathrm{N}_{2}$ gas. After the oxidative annealing in air at $200{ }^{\circ} \mathrm{C}$ for $4 \mathrm{~h}$, the surface of the copper layer was also observed by SEM (Fig. 3). The images in Fig. 3 are quite different from those shown in Fig. 2. In Fig. 3a (the secondary electron image), a rough surface of large spherical particles and small prominences (which appear to be spherical particles) was observed. The large particles were connected via the small $10 \mathrm{~nm}$ size prominences. The BEICOMPO image (Fig. 3b) indicated that the smaller prominences, with their bright contrast, consisted of copper. However, a comparison of these two images revealed that the organic components were not completely removed by this oxidative annealing. The areas marked by arrows in Fig. 3b, for example, are considered as organic components based on a comparison of the two SEM images.

X-ray diffractograms of the copper layers before and after annealing are displayed in Fig. 4. As discussed in our previous paper, ${ }^{35}$ the copper fine particles were not oxidized in their powder form. After they were re-dispersed in a copper particle paste and flatly printed on an $\mathrm{Al}_{2} \mathrm{O}_{3}$ substrate, a small, broad peak corresponding to $\mathrm{Cu}_{2} \mathrm{O}(111)\left(2 \theta=36.4^{\circ}\right)$ was observed. After annealing in air, this peak became larger but remained broad, suggesting that a small quantity of $\mathrm{Cu}_{2} \mathrm{O}$ was generated on the copper particle surface, corresponding to the SEM images in Fig. 3. After annealing in air, the copper layer contained $29 \mathrm{wt} \%$ $\mathrm{Cu}_{2} \mathrm{O}$ and $71 \mathrm{wt} \%$ metallic copper, calculated using the reference intensity ratio (RIR) method.

The annealed substrates were then again annealed at $200{ }^{\circ} \mathrm{C}$, but the gas was changed to $3 \% \mathrm{H}_{2}$ in $\mathrm{N}_{2}$ gas mixture (reductive annealing). The reductive annealing time was varied from 1 to $4 \mathrm{~h}$. As observed in Fig. 4, the XRD peak intensity corresponding to $\mathrm{Cu}_{2} \mathrm{O}$ decreases with the reductive annealing time. First, the surface of the film containing $\mathrm{Cu}_{2} \mathrm{O}$ was partially reduced to form copper under reductive annealing for $1 \mathrm{~h}$ (Fig. 4c). Compared with the XRD patterns of oxidative annealed films (Fig. 4b), the very small change in intensity of $\mathrm{Cu}_{2} \mathrm{O}$ peaks can be observed. A
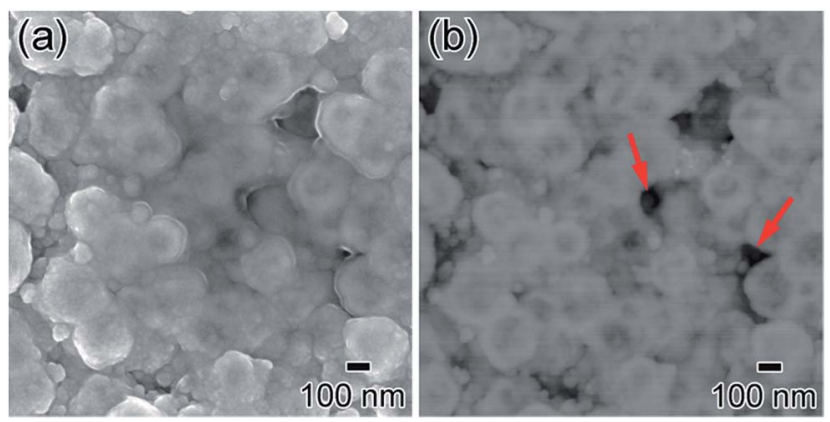

Fig. 3 SEM images of the copper particle layer surface after oxidative annealing. (a) A SEI (secondary electron) image and (b) a BEI-COMPO (back scattered electron for composition) image, with the red arrows marking areas of organic material.

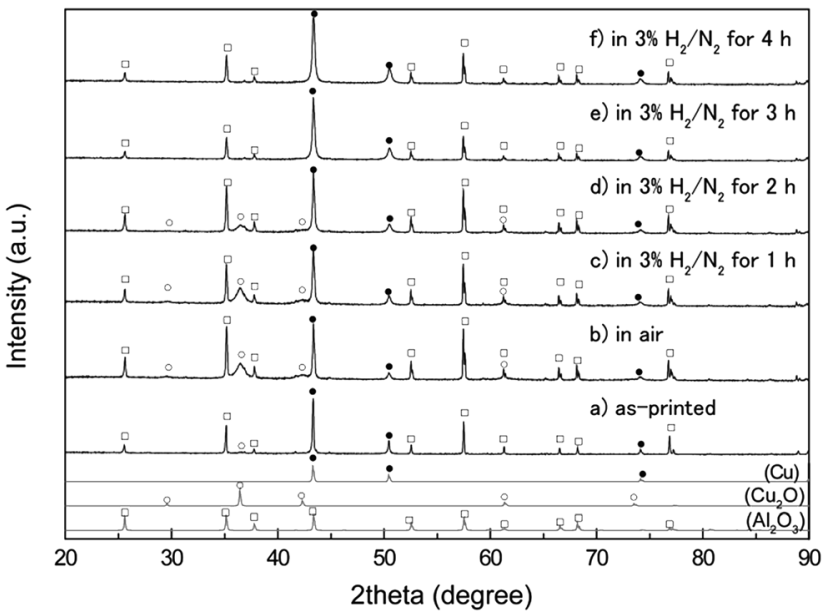

Fig. 4 XRD patterns of the copper layer on an $\mathrm{Al}_{2} \mathrm{O}_{3}$ substrate before and after annealing. (a) The as-printed copper layer, (b) the layer after oxidative annealing, and the layer after reductive annealing for (c) $1 \mathrm{~h}$, (d) $2 \mathrm{~h}$, (e) $3 \mathrm{~h}$, and (f) $4 \mathrm{~h}$. The metallic copper, the $\mathrm{Cu}_{2} \mathrm{O}$, and the $\mathrm{Al}_{2} \mathrm{O}_{3}$ peaks are marked as closed circles $(\mathbf{O})$, open circles $(O)$, and open squares ( $\square$ ), respectively.

resistivity of the oxidative annealed film was $25 \Omega \mathrm{cm}$, which indicates that the oxidative annealed film was not conductive. The resistivity dramatically changed, however, after $1 \mathrm{~h}$ of reductive annealing, to $7.4 \times 10^{-5} \Omega \mathrm{cm}$. Thus, reductive annealing makes the film electro-conductive. This is probably due to the connecting of surface metallic copper which was generated by the reductive annealing. The surface metallic copper formed necking during reductive annealing and increased the conductivity. But this reduction of $\mathrm{Cu}_{2} \mathrm{O}$ to $\mathrm{Cu}$ cannot be observed in the XRD patterns. After additional $1 \mathrm{~h}$ of reductive annealing, more than half of $\mathrm{Cu}_{2} \mathrm{O}$ was reduced to metallic copper (Fig. $4 \mathrm{c}$ and d). The resistivity and the average thickness of the film reduced for $2 \mathrm{~h}$ were $2.7 \times 10^{-5} \Omega \mathrm{cm}$ and $3.3 \mu \mathrm{m}$ (Fig. $6 \mathrm{c}$ ).

The XRD pattern (Fig. 4e) indicates that $\mathrm{Cu}_{2} \mathrm{O}$ was completely reduced by annealing for more than $3 \mathrm{~h}$ at $200{ }^{\circ} \mathrm{C}$, and a low resistivity of $8.2 \times 10^{-6} \Omega \mathrm{cm}$ was achieved. A very small peak observed at $36.88^{\circ}$ in Fig. 4 e and $\mathrm{f}$ (which cannot be found in the $\mathrm{Al}_{2} \mathrm{O}_{3}$ pattern of JCPDS card) can be attributed to the $\mathrm{Al}_{2} \mathrm{O}_{3}$ substrate used for sintering (Fig. S4 $\dagger$ ). This resistivity is almost 5 times of that of the bulk copper $\left(1.7 \times 10^{6} \Omega \mathrm{cm}\right)$. Thus, the complete reduction of the inside $\mathrm{Cu}_{2} \mathrm{O}$ is necessity to achieve the low resistivity. Additional $1 \mathrm{~h}$ of reductive annealing (total $4 \mathrm{~h}$ ) did not decrease the resistivity. Resistivities of the reductive annealed films are summarized in Fig. 5. On the other hand, TG measurement of commercially available $\mathrm{Cu}_{2} \mathrm{O}$ particles was performed in this mixed reductive gas, and the change in mass versus time is shown in Fig. $\mathrm{S} 3 . \dagger$ The $\mathrm{Cu}_{2} \mathrm{O}$ had a slight change in mass under $3 \% \mathrm{H}_{2}$ in $\mathrm{N}_{2}$ during the reduction at $200{ }^{\circ} \mathrm{C}$ for 2 h. Thus, $\sim 2 \mu \mathrm{m}$ size $\mathrm{Cu}_{2} \mathrm{O}$ particles (SEM image shown in Fig. $\mathrm{S} 5 \dagger$ ) are not usually reduced by these conditions. However, the XRD patterns of the reduced films revealed that the $\mathrm{Cu}_{2} \mathrm{O}$ was completely reduced at $200{ }^{\circ} \mathrm{C}$ for $3 \mathrm{~h}$ of annealing time, forming metallic copper. We will discuss below about the mechanism of $\mathrm{Cu}_{2} \mathrm{O}$ reduction at a lower temperature. 
The surface and cross-sectional SEM images after this reductive annealing step for $2 \mathrm{~h}$ are shown in Fig. 6 . Necking ${ }^{\mathbf{4 5 - 4 9}}$ of the copper particles and connections between particles were clearly observed in SEI image of Fig. 6a. The cross-sectional image (Fig. 6c) clearly indicates that the necking and connections were observed not only at the surface region but also near the substrate. Fig. $6 \mathrm{~b}$ shows the BEI-COMPO image of the copper layer surface. Compared with Fig. 6a, the areas marked by arrows can be considered the organic components.

\section{High-resolution TEM (HRTEM) observation of copper layers after annealing}

For further investigation, we carried out a HRTEM observation of the annealed copper thin film scratched from the $\mathrm{Al}_{2} \mathrm{O}_{3}$ substrate (Fig. 7). As shown in Fig. 7c, after heating under airflow at $200^{\circ} \mathrm{C}$, small prominences less than $c a .10 \mathrm{~nm}$ in size were evident on the surface of the copper particles. These nanosized $\mathrm{Cu}_{2} \mathrm{O}$ were clearly observed in our previous report about the in situ heating TEM observation of $\mathrm{Cu}$ oxidation. ${ }^{45}$ The lattice fringe distances $(2.5 \AA$ and $3.1 \AA$ ) observed in the HRTEM images shown in Fig. 7e and $\mathrm{f}$ allowed us to identify these prominences as $\mathrm{Cu}_{2} \mathrm{O}$ (111) and (110), respectively. These images strongly support a formation mechanism of the oxidative annealing in air at $200{ }^{\circ} \mathrm{C}$ producing small prominences of $\mathrm{Cu}_{2} \mathrm{O}(<10 \mathrm{~nm})$ covering the metallic copper particles.

Fig. $7 \mathrm{~g}-\mathrm{j}$ show the TEM images of the copper film annealed under the reductive gas for $2 \mathrm{~h}$ ( $\mathrm{g}$ and $\mathrm{h}$ ) $4 \mathrm{~h}$ ( $\mathrm{i}$ and j). Fig. $7 \mathrm{~g}$ and $\mathrm{h}$ are displaying the necked particles. During the oxidation of the copper particle surface, the diffusion of oxygen ions and copper ions into the surface of copper particle first occurs, resulting in formation of copper oxides. ${ }^{45}$ Then, the particle swelled due to the difference in density between the copper $\left(8.94 \mathrm{~g} \mathrm{~cm}^{-3}\right)$ and copper oxide $\left(\mathrm{Cu}_{2} \mathrm{O}: 6.04 \mathrm{~g} \mathrm{~cm}^{-3}\right)$. This swelling allowed the particle surface to partially contact nearby particles, resulting in an aggregate formation suitable for sintering. The prominences that were below $10 \mathrm{~nm}$ in size could

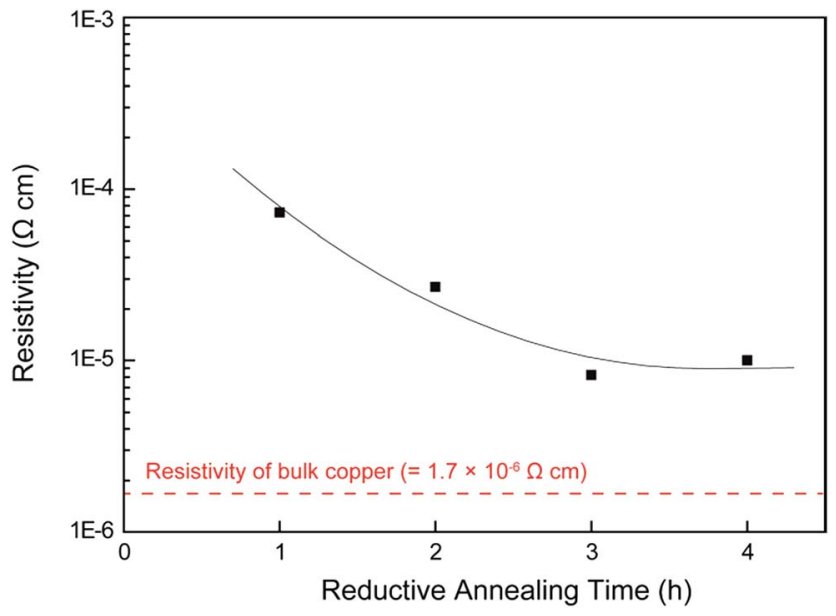

Fig. 5 Resistivity of the reductive annealed copper films with various annealing time. The resistivity of bulk copper $\left(1.7 \times 10^{-6} \Omega \mathrm{cm}\right)$ is marked as the red dotted line.

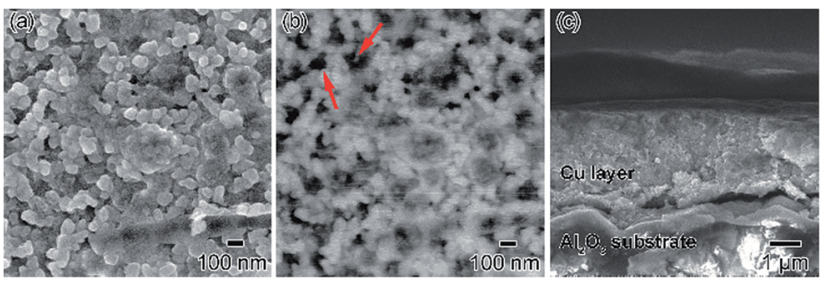

Fig. 6 SEM images of copper layers printed on an $\mathrm{Al}_{2} \mathrm{O}_{3}$ substrate after the reductive annealing for $2 \mathrm{~h}$. (a) A SEl image of the surface. (b) A BEICOMPO image of the surface with the red arrows marking areas of organic material. (c) A cross-sectional image of the reduced layer.

lead to the necking between particles. Thus, sintering of the particles progressed due to the melting point depression resulting from the $\mathrm{Cu}_{2} \mathrm{O}$ nanoscale prominences (generated in the heating under air) reducing to form copper again. The selected area electron diffraction (SAED) image of the copper layer after the reductive sintering is shown in Fig. 7j. The
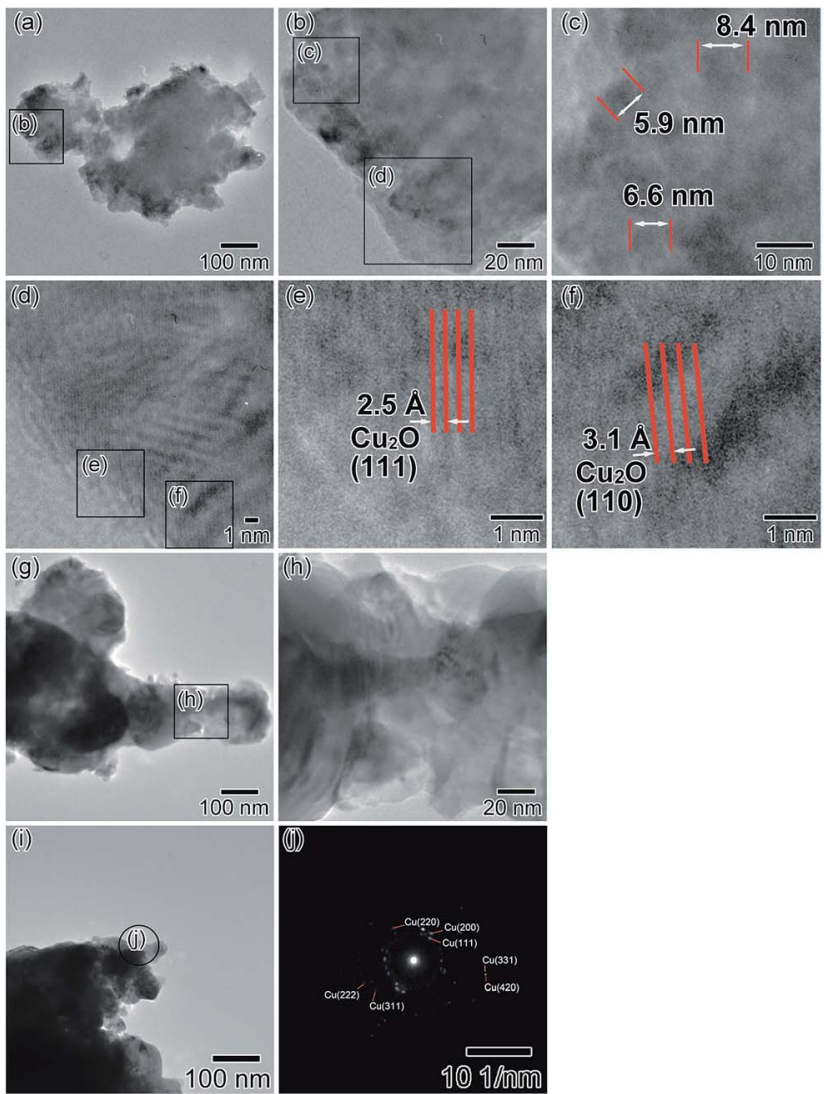

Fig. 7 (a-f) TEM images of the copper particles after oxidative annealing in air, (b) larger magnification image of the boxed area shown in (a). ( $c$ and d) A HRTEM image with a higher magnification of the boxed area in (b). Small particles ca. $10 \mathrm{~nm}$ in size can be observed in (c). (e and f) Lattice fringes of the $\mathrm{Cu}_{2} \mathrm{O}$ (111) and (110), respectively, can be observed. (g) TEM image of the copper particles after the reductive annealing of $2 \mathrm{~h}$. (h) Enlarged TEM image of the part of $(\mathrm{g})$ with a higher magnification. (i) TEM image of the copper particles after the reductive annealing for $4 \mathrm{~h}$. (j) Selected area electron diffraction (SAED) image of the square shown in (i). Diffraction spots are assigned as metallic copper. 
diffraction spots indicate that the obtained layer was consisted of metallic copper.

\section{Low-temperature sintering mechanism of the submicrometer- sized copper fine particles that produces electro-conductive layers}

Fig. 8 shows the TG result of copper particles paste. The measurement was carried out under air flow $\left(200 \mathrm{~cm}^{3} \mathrm{~min}^{-1}\right)$ with the heating rate of $0.5{ }^{\circ} \mathrm{C} \mathrm{min}^{-1}$. The liquid component of paste $(48 \mathrm{wt} \%)$ was firstly evaporated below $120{ }^{\circ} \mathrm{C}$. After measurement, the copper was completely oxidized and changed into $\mathrm{CuO}$. However, the value of $56.3 \mathrm{wt} \%$ includes the weight loss of decomposed polymer components such as the gelatin, the dispersing agent, and the ethyl cellulose. The initial copper ratio of the paste can be calculated as $0.563 / 1.25=0.450$ with use of the ratio of $\mathrm{MW}(\mathrm{CuO}) / \mathrm{MW}(\mathrm{Cu})=79.545 / 63.546=1.25$. Thus, the amount of the polymer is calculated as $52.0-45.0=7$ wt $\%$. It contains not only gelatin but also vehicles, ethyl cellulose, required to obtain a stable paste. The detailed oxidation behavior of copper particles can be observed between 100 and $250{ }^{\circ} \mathrm{C}$. The gelatin-stabilized metallic copper particles can be oxidized at higher temperatures than $c a .120{ }^{\circ} \mathrm{C}$ under air. $\mathrm{Cu}_{2} \mathrm{O}$ forms initially on the copper particle surface then. The mass in the TG thermogram increased above $120^{\circ} \mathrm{C}$, before decreasing again above $165{ }^{\circ} \mathrm{C}$. As shown in the TG thermogram of the paste vehicle used in this study (Fig. S3 $\dagger$ ), the decomposition of ethyl cellulose in the commercial paste vehicle starts at $160{ }^{\circ} \mathrm{C}$ and lasts at temperatures higher than $200{ }^{\circ} \mathrm{C}$. Therefore, annealing at $200{ }^{\circ} \mathrm{C}$ is insufficient to eliminate all the organic components from the copper paste. Fig. 9 shows TG result of the sintered copper film with $3 \mathrm{~h}$ of reductive annealing. TG measurement was also carried out under air flow $\left(200 \mathrm{~cm}^{3}\right.$ $\min ^{-1}$ ) and the heating rate of $5{ }^{\circ} \mathrm{C} \mathrm{min}^{-1}$. The oxidation of $\mathrm{Cu}$ started at $c a .120^{\circ} \mathrm{C}$. Above $160^{\circ} \mathrm{C}$, the decomposition of polymers occurred at the same time. After measurement, the copper was completely oxidized and changed into CuO. However, the value of $117 \mathrm{wt} \%$ also includes the weight loss of decomposed organic components. The initial copper ratio of sintered sample can be calculated as 1.17/1.25 $=0.94$. From this result, we can estimate that the copper layer after sintering contained $6 \mathrm{wt} \%$ of organic components. The copper paste used to prepare copper layer contained $7 \mathrm{wt} \%$ of polymers, including gelatin, dispersant and ethyl cellulose.

With our low temperature sintering, all organic components were not removed from the copper layer by sintering. However, formation of prominences of $\mathrm{Cu}_{2} \mathrm{O}$ by oxidative sintering followed by the reductive sintering at a low temperature generated metallic copper neckings to form a conductive copper layer. These results indicate that the polymers used for the copper paste can play also an important role of antioxidizing stabilizers of the sintered metallic copper layer under ambient conditions.

From the results and discussion above, the sintering mechanism of our two-step annealing process can be illustrated, as shown in Fig. 10. First, the copper fine particles were surrounded by an organic layer. Then, the diffusion of oxygen ions and copper ions into the surface of copper particle occurred ${ }^{45}$

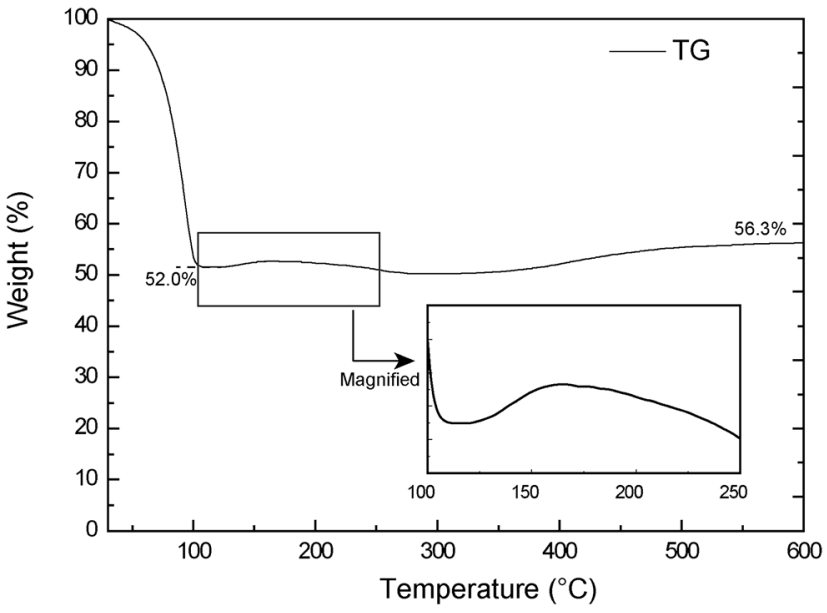

Fig. 8 Thermogravimetric (TG) curve of the gelatin-stabilized copper paste. The heating rate was $0.5^{\circ} \mathrm{C} \mathrm{min}{ }^{-1}$. (Inset) An enlarged view of the TG curve between 100 and $250{ }^{\circ} \mathrm{C}$, showing an increase in the mass beginning at $120^{\circ} \mathrm{C}$, then decreasing again above $165^{\circ} \mathrm{C}$.

and small prominences of $\mathrm{Cu}_{2} \mathrm{O}, c a .10 \mathrm{~nm}$ in size, which were attached to the copper fine particles, were produced via the oxidative annealing. As the grass transition temperature $\left(T_{\mathrm{g}}\right)$ of gelatin is about $80{ }^{\circ} \mathrm{C}$, gas molecules can be penetrate and diffused easily in the polymer layers and can react with copper and copper oxide surfaces. Finally, these $\mathrm{Cu}_{2} \mathrm{O}$ prominences were reduced again to form the particle necking. Kim et al. reported the time-dependent reduction of $\mathrm{Cu}_{2} \mathrm{O}$ powder under $5 \% \mathrm{H}_{2}$ in $\mathrm{Ar}$ gas at $200{ }^{\circ} \mathrm{C} .{ }^{50}$ They also showed that a higher reduction temperature gives a shorter sintering period and the reduction of $\mathrm{Cu}_{2} \mathrm{O}$ powder at $200{ }^{\circ} \mathrm{C}$ completed in $450 \mathrm{~min}$. Our reduction completed much faster than their result. In our system, the $\mathrm{Cu}_{2} \mathrm{O}$ particle size is less than $10 \mathrm{~nm}$ as shown in

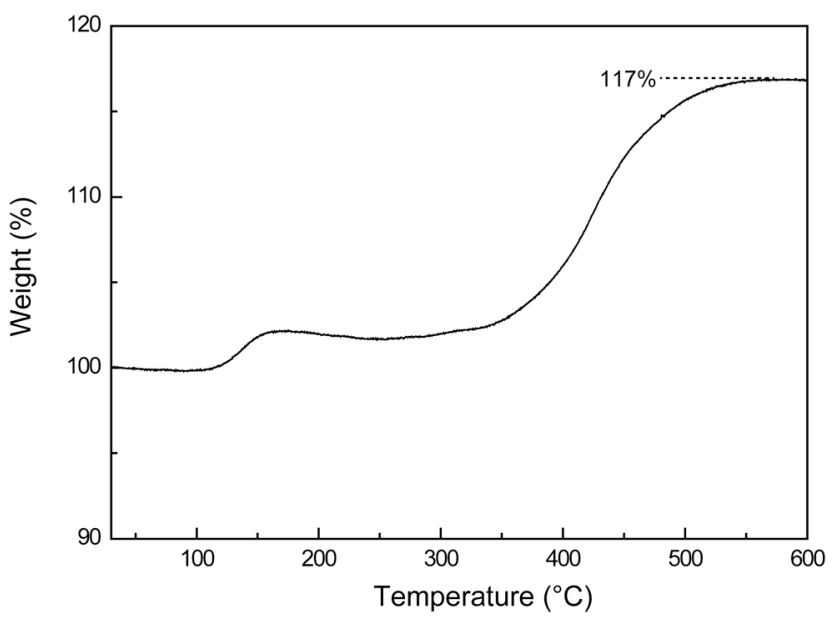

Fig. 9 TG chart of the sintered copper film with $3 \mathrm{~h}$ of reductive annealing. The sample was scratched from a glass substrate. TG measurement was carried out under air flow $\left(200 \mathrm{~mL} \mathrm{~min}^{-1}\right)$ and the heating rate of $5{ }^{\circ} \mathrm{C} \mathrm{min}^{-1}$. After measurement, the copper changed into the copper oxide $(\mathrm{CuO})$, so that the initial copper ratio was $\mathrm{MW}(\mathrm{Cu}) / \mathrm{MW}(\mathrm{CuO})=117 / 125=0.94$. The organic component ratio was estimated as $6 \mathrm{wt} \%$. 


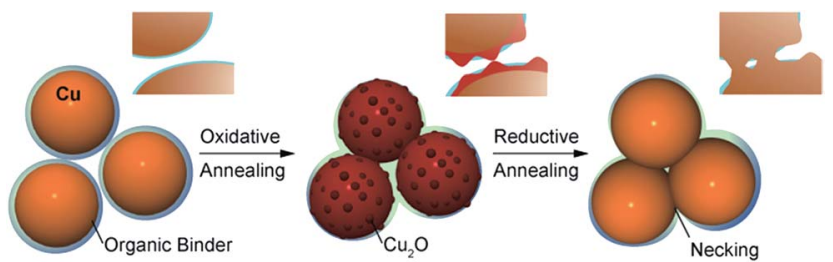

Fig. 10 Schematic of the necking and connection formation between the copper fine particles by our two-step annealing process.

Fig. $7 \mathrm{~b}$ and in the previous in situ TEM observation. ${ }^{46}$ Compared with micro- and nano-particles, the $\mathrm{Cu}_{2} \mathrm{O}$ particle size may strongly affect their reduction. If the particle size of $\mathrm{Cu}_{2} \mathrm{O}$ is larger than $1 \mu \mathrm{m}$, the reduction temperature increases above $400{ }^{\circ} \mathrm{C} .{ }^{51}$ At $200{ }^{\circ} \mathrm{C}$, only $3 \mathrm{wt} \%$ of $\mathrm{Cu}_{2} \mathrm{O}$ micro-particles $(\sim 2 \mu \mathrm{m})$ were reduced under $3 \% \mathrm{H}_{2}$ in $\mathrm{N}_{2}$ gas for $20 \mathrm{~h}$ of annealing (Fig. S5 and S6†). This result indicates that only $10 \mathrm{~nm}$ of depth from the surface were reduced. Thus, the $\mathrm{Cu}_{2} \mathrm{O}$ particles size of $10 \mathrm{~nm}$ is enough small to enable an easy reduction. Our sintering mechanism can be explained that the nano-sized $\mathrm{Cu}_{2} \mathrm{O}$ prominences enable and accelerate the reduction at lowtemperature. Using this two-step annealing, we successfully achieved the low resistivity due to formation of particle necking without removing all polymer layers.

\section{Conclusions}

In conclusion, we performed an oxidative-reductive two-step annealing at $200{ }^{\circ} \mathrm{C}$ of $130 \mathrm{~nm}$ sized copper fine particles to obtain a highly conductive copper layer, even though the organic components included in the copper fine particle paste did not fully decompose at this temperature. After annealing the copper layer in air, $\mathrm{Cu}_{2} \mathrm{O}$ prominences with the size of less than $10 \mathrm{~nm}$ were generated on the copper particle surface, connecting together through the organic layers. These $\mathrm{Cu}_{2} \mathrm{O}$ nanoprominences could then be reduced to generate metallic copper nanoparticles, connecting the copper cores. Necking of the copper fine particles were observed along with their connections after the reductive annealing. The obtained film resistivity was as low as $8.2 \times 10^{-6} \Omega \mathrm{cm}$. Our results clearly indicate that using small copper nanoparticles is not the only solution for a low-temperature sintering process.

\section{Acknowledgements}

This work is partially supported by Grant-in-Aid for Scientific Research A (24241041 to TY) from JSPS, Japan, NEDO, Japan and The Shinsei Foundation, Japan. We also thank Nitta Gelatin Inc. for gelatin supply.

\section{Notes and references}

1 Nanoparticles, ed. G. Schmid, Wiley-VCH, Weinheim, 2011.

2 N. Li, P. Zhao and D. Astruc, Angew. Chem., Int. Ed., 2014, 53, 1756-1789.
3 N. Yan, C. Xiao and Y. Kou, Coord. Chem. Rev., 2010, 254, 1179-1218.

4 N. Toshima and T. Yonezawa, New J. Chem., 1998, 22, 11791201.

5 S. Kango, S. Kalia, A. Celli, J. Njuguna, Y. Habibi and R. Kumar, Prog. Polym. Sci., 2013, 38, 1232-1261.

6 F. Viñes, J. R. B. Gomes and F. Illas, Chem. Soc. Rev., 2014, 43, 4922-4939.

7 N. Toshima, T. Yonezawa and K. Kushihashi, J. Chem. Soc., Faraday Trans., 1993, 89, 2537-2543.

8 Z. Zhang, H. Che, Y. Wang, X. She, J. Sun, P. Gunawan, Z. Zhong and F. Su, ACS Appl. Mater. Interfaces, 2012, 4, 1295-1302.

9 S. Liu, Y. Wang, Y. Zhu, G. Wang, Z. Zhang, H. Che, L. Jia and F. Su, RSC Adv., 2014, 4, 7826-7833.

10 S. Chernousova and M. Epple, Angew. Chem., Int. Ed., 2013, 52, 1636-1653.

11 K. Kawai, T. Narushima, K. Kaneko, H. Kawakami, M. Matsumoto, A. Hyono, H. Nishihara and T. Yonezawa, Appl. Surf. Sci., 2012, 262, 76-80.

12 K. Saha, S. S. Agasti, C. Kim, X. Li and V. M. Rotello, Chem. Rev., 2012, 112, 2739-2779.

13 P. K. Jain, X. Huang, I. H. El-Sayed and M. A. El-Sayed, Plasmonics, 2007, 2, 107-118.

14 T. Yonezawa, S. Takeoka, H. Kishi, K. Ida and M. Tomonari, Nanotechnology, 2008, 19, 145706.

15 Y.-C. Liao and Z.-K. Kao, ACS Appl. Mater. Interfaces, 2012, 4, 5109-5113.

16 W. Shen, X. Zhang, Q. Huang, Q. Xu and W. Song, Nanoscale, 2014, 6, 1622-1628.

17 Y. Zhang, P. Zhu, G. Li, T. Zhao, X. Fu, R. Sun, F. Zhou and C.-p. Wong, ACS Appl. Mater. Interfaces, 2014, 6, 560-567.

18 S. Krishnan, A. S. M. A. Haseeb and M. R. Johan, IEEE Trans. Compon., Packag., Manuf. Technol., 2012, 2, 587-592.

19 T. Wang, X. Chen, G.-Q. Lu and G.-Y. Lei, J. Electron. Mater., 2007, 36, 1333-1340.

20 H. Alarifi, A. Hu, M. Yavuz and Y. N. Zhou, J. Electron. Mater., 2011, 40, 1394-1402.

21 X.-F. Tang, Z.-G. Yang and W.-J. Wang, Colloids Surf., A, 2010, 360, 99-104.

22 C.-L. Lee, K.-C. Chang and C.-M. Syu, Colloids Surf., A, 2011, 381, 85-91.

23 D. Mott, J. Galkowski, L. Wang, J. Luo and C.-J. Zhong, Langmuir, 2007, 23, 5740-5745.

24 A. C. Arias, J. D. MacKenzie, I. MacCulloch, J. Rivnay and A. Salleo, Chem. Rev., 2010, 110, 3-24.

25 J. Perelaer, P. J. Smith, D. Mager, D. Soltman, S. K. Volkman, V. Subramanian, J. G. Korvink and U. S. Schubert, J. Mater. Chem., 2010, 20, 8446-8453.

26 D. Deng, Y. Jin, Y. Cheng, T. Qi and F. Xiao, ACS Appl. Mater. Interfaces, 2013, 5, 3839-3846.

27 A. Yabuki and N. Arriffin, Thin Solid Films, 2010, 518, 70337037.

28 A. Yabuki, N. Arriffin and M. Yanase, Thin Solid Films, 2011, 519, 6530-6533.

29 G. Qin, A. Watanabe, H. Tsukamoto and T. Yonezawa, Jpn. J. Appl. Phys., 2014, 53, 096501. 
30 B. Kang, S. Han, J. Kim, S. Ko and M. Yang, J. Phys. Chem. C, 2011, 115, 23664-23670.

31 B.-Y. Wang, T.-H. Yoo, Y.-W. Song, D.-S. Lim and Y.-J. Oh, ACS Appl. Mater. Interfaces, 2013, 5, 4113-4119.

32 T. Ishizaki and R. Watanabe, J. Mater. Chem., 2012, 22, 25198-25206.

33 W.-S. Han, J.-M. Hong, H.-S. Kim and Y.-W. Song, Nanotechnology, 2011, 22, 395705.

34 S. Magdassi, M. Grouchko and A. Kamyshny, Materials, 2010, 3, 4626-4638.

35 M. Tomonari, K. Ida, H. Yamashita and T. Yonezawa, J. Nanosci. Nanotechnol., 2008, 8, 2468-2471.

36 T. Yonezawa, N. Nishida and A. Hyono, Chem. Lett., 2010, 39, 548-549.

37 Y. Lee, J.-r. Choi, K. J. Lee, N. E. Stott and D. Kim, Nanotechnology, 2008, 19, 415604.

38 Y. Jianfeng, Z. Guisheng, H. Anming and Y. N. Zhou, J. Mater. Chem., 2011, 21, 15981-15986.

39 J. Xiong, Y. Wang, Q. Xue and X. Wu, Green Chem., 2011, 13, 900-904.

40 Y. Kobayashi and T. Sakuraba, Colloids Surf., A, 2008, 317, 756-759.

41 M. Grouchko, A. Kamyshny and S. Magdassi, J. Mater. Chem., 2009, 19, 3057-3062.
42 J. S. Kang, H. S. Kim, J. Ryu, J. H. T. Hahn, S. Jang and J. W. Joung, J. Mater. Sci.: Mater. Electron., 2010, 21, 12131220.

43 K. Ida, M. Tomonari, Y. Sugiyama, Y. Chujyo, T. Tokunaga, T. Yonezawa, K. Kuroda and K. Sasaki, Thin Solid Films, 2012, 520, 2789-2793.

44 Y. Yong, T. Yonezawa, H. Tsukamoto and M. Matsubara, J. Mater. Chem. C, 2015, 3, 5890-5895.

45 T. Yonezawa, Y. Uchida and Y. Abe, J. Nanosci. Nanotechnol., 2014, 14, 5402-5407.

46 T. Narushima, H. Tsukamoto and T. Yonezawa, AIP Adv., 2012, 2, 042113.

47 W.-r. Lee, Y. S. Lim, S. Kim, J. Jung, Y.-K. Han, S. Yoon, L. Piao and S.-H. Kim, J. Mater. Chem., 2011, 21, 6928-6933.

48 D. Demirskyi, D. Agrawal and A. Ragulya, Scr. Mater., 2010, 62, 552-555.

49 Y. Kobayashi, T. Shirochi, Y. Yasuda and T. Morita, Int. J. Adhes. Adhes., 2012, 33, 50-55.

50 J. Y. Kim, J. A. Rodriguez, J. C. Hanson, A. I. Frenkel and P. L. Lee, J. Am. Chem. Soc., 2003, 125, 10684-10692.

51 Y. Yasuda, E. Ide and T. Morita, Open Surf. Sci. J., 2011, 3, 123-130. 